\title{
Xuất bản quốc tế về khoa học của Việt Nam: chính sách và xu thế
}

\author{
Hoàng Khánh Linh
}

\section{TẠP CHÍ GIÁO DỤC}

$05 / 11 / 2020$

https://tapchigiaoduc.moet.gov.vn/vi/news/print/thong-tin-khoa-hoc/xuat-ban-quoc-te-vekhoa-hoc-cua-viet-nam-chinh-sach-va-xu-the-606.html 


\title{
Xuất bản quốc tế về khoa học của Việt Nam: chính sách và xu thế
}

\author{
Thứ năm - 05/11/2020 09:16
}

Từ năm1986 đến năm 2008, xuất bản quốc tế hầu như không tồn tại trên thực tế trong giới học thuật, ngoại trừ trong cộng đồng toán học. Nghiên cứu này xem xét việc sử dụng xuất bản quốc tế (tức là xuất bản trên các tạp chí/sách được lập chỉ mục bởi cơ sở dữ liệu quốc tế) trong giới học thuật ở Việt Nam kể từ Đổi mới năm 1986. Phân tích tài liệu và phỏng vấn sâu với 20 học giả Việt Nam đã được thực hiện để giải quyết mục tiêu nghiên cứu. Kết quả nghiên cứu cho thấy ba cột mốc quan trọng trong phát triển học thuật: 1986-2008, 2008-2017 và 2017 cho đến nay, thể hiện những bước tiến nhất định và mở ra tương lai đối với xuất bản quốc tế tại Việt Nam. Trong thời gian tới, các nhà hoạch định chính sách và các nhà lãnh đạo học thuật ở Việt Nam được khuyến nghị sử dụng nhiều hơn nữa các thước đo xuất bản quốc tế để nâng cao chất lượng và kết quả nghiên cứu quốc tế.

Từ năm1986 đến năm 2008, xuất bản quốc tế hầu như không tồn tại trên thực tế trong giới học thuật, ngoại trừ trong cộng đồng toán học. Nghiên cứu này xem xét việc sử dụng xuất bản quốc tế (tức là xuất bản trên các tạp chí/sách được lập chỉ mục bởi cơ sở dữ liệu quốc tế) trong giới học thuật ở Việt Nam kể từ Đổi mới năm 1986. Phân tích tài liệu và phỏng vấn sâu với 20 học giả Việt Nam đã được thực hiện để giải quyết mục tiêu nghiên cứu. Kết quả nghiên cứu cho thấy ba cột mốc quan trọng trong phát triển học thuật: 1986-2008, 2008-2017 và 2017 cho đến nay, thể hiện những bước tiến nhất định và mở ra tương lai đối với xuất bản quốc tế tại Việt Nam. Trong thời gian tới, các nhà hoạch định chính sách và các nhà lãnh đạo học thuật ở Việt Nam được khuyến nghị sử dụng nhiều hơn nữa các thước đo xuất bản quốc tế để nâng cao chất lượng và kết quả nghiên cứu quốc tế.

Dưới đây, Tạp chí Giáo dục trân trọng lược dịch và giới thiệu quý bạn đọc về phân tích của Thi Thu Ha Nguyen, Hiep-Hung Pham, QuanHoang Vuong, Quoc-Thai Cao, Viet-Hung Dinh và Dinh Duc Nguyen (2020) trong bài viết với tiêu đề "The adoption of international publishing within Vietnamese academia from 1986 to 2020: A review", tạm dịch là "Việc tiếp nhận xuất bản quốc tế trong giới học thuật Việt Nam từ năm 1986 đến năm 2020: Đánh giá".

Xuất bản quốc tế (tức là xuất bản trên các tạp chí/sách được lập chỉ mục bởi cơ sở dữ liệu quốc tế) đã phổ biến trong giới học thuật trên toàn thế giới trong nhiều thập kỉ. Trong số các cơ sở dữ liệu xuất bản quốc tế, Clarivate Web of Science (WoS) và Scopus là những cơ sở dữ liệu nổi bật nhất và được sử dụng rộng rãi bởi các trường đại học lớn. Ở cấp độ quốc gia và tổ chức, WOS và Scopus cũng đóng những vai trò quan trọng; việc sử dụng cơ sở dữ liệu WOS và Scopus nhằm tạo ra một hệ thống tài trợ nghiên cứu dựa trên hiệu suất đã được thực hiện để thay thế các hệ thống học thuật hiện có.

Tại Việt Nam, xuất bản quốc tế hiện đã chiếm vị trí quan trọng trong các chính sách học thuật và thực tiễn. Cụ thể, việc có các công trình nghiên cứu được công bố trong các cơ sở dữ liệu được lập chỉ mục quốc tế như Web of Science (WOS) hoặc Scopus đã trở thành điều kiện tiên quyết để tốt nghiệp Tiến sĩ, bổ nhiệm giáo sư, phó giáo sư và tài trợ nghiên cứu. Các thuật ngữ về xuất bản quốc tế, công bố quốc tế đã xuất hiện thường xuyên trên các phương tiện truyền thông đại chúng. Tuy nhiên, chưa có nghiên cứu nào được thực hiện để xem xét nguồn gốc và sự phát triển của xuất bản quốc tế trong các chính sách và thực tiễn học thuật ở Việt Nam. Với một cái nhìn tổng thể có hệ thống về tiến độ và hiệu quả của quá trình hội nhập xuất bản quốc tế, nghiên cứu này không chỉ có giá trị đối với các nhà hoạch định chính sách và học giả Việt Nam mà còn đối với các nước khác như một tài liệu tham khảo học tập. Nghiên cứu này cũng vạch ra những hướng tiềm năng để tiếp tục áp dụng xuất bản quốc tế ở Việt Nam.

Nghiên cứu này nhằm trả lời 4 câu hỏi:

(1) Những dấu mốc quan trọng đối với xuất bản quốc tế ở Việt Nam?

(2) Vai trò của xuất bản quốc tế đã phát triển như thế nào ở Việt Nam trong từng giai đoạn?

(3) Các bên liên quan chính là ai và vai trò của họ trong việc đạt được từng mốc quan trọng?

(4) Định hướng tương lai cho xuất bản quốc tế tại Việt Nam?

Để giải quyết mục tiêu nghiên cứu, bài viết đã sử dụng phân tích tài liệu để xem xét các tài liệu hiện có liên quan đến công bố quốc tế ở Việt Nam, bao gồm thông cáo báo chí, báo cáo thể chế, hồ sơ công khai và văn bản pháp lí. Đặc biệt, các cuộc phỏng vấn sâu đã được thực hiện với 20 học giả Việt Nam, họ đều có kinh nghiệm về xuất bản quốc tế trong khoảng thời gian của nghiên cứu (1986-2000) thông qua các hoạt động bao gồm thực hiện nghiên cứu, đánh giá, chỉnh sửa hoặc tư vấn/phát triển các chính sách học thuật. Các cuộc phỏng vấn sâu được diễn ra trong khoảng thời gian từ tháng 1-2/2020. Phạm vi nghiên cứu trong hơn 30 năm, bắt đầu từ năm 1986 đến nay, thành ba giai đoạn chính:

- Giai đoạn 1 (Thời kì Đổi mới 1986-2008): Không có chính sách về xuất bản quốc tế. Nhiều trở ngại đối với các trường đại học và viện nghiên cứu đã hạn chế kết quả nghiên cứu của Việt Nam. Các viện nghiên cứu chật vật về kinh phí nghiên cứu và không giữ được các nhà khoa học tài năng. Nhìn chung, hệ thống giáo dục lạc hậu, thiếu đánh giá chất lượng cho nghiên cứu và phân bổ ngân sách. Tuy nhiên, giai đoạn này cũng chứng kiến những nỗ lực trong một số ít lĩnh vực (như toán học), đã có sự tham gia vào xuất bản quốc tế.

- Giai đoạn 2 (2008-2017): Bắt đầu xuất bản quốc tế trong giới học thuật. Được đánh dấu bằng sự ra đời của quỹ NAFOSTED thuộc Bộ Khoa học và Công nghệ, dẫn đến một bước nhảy vọt lớn về đầu ra trong cơ sở dữ liệu xuất bản quốc tế. Một trong những đặc điểm chính của thời kì thứ hai là nâng cao nhận thức của xã hội về tầm quan trọng và vai trò của xuất bản quốc tế.

- Giai đoạn 3 (2017-hiện nay): Hình thành và mở rộng. Đây được xem là bước đột phá trong chính sách học thuật với việc ra mắt chính sách cải cách đào tạo tiến sĩ vào năm 2017 và quy định mới về chức danh giáo sư vào năm 2018. Hai chính sách mới này nhấn mạnh vai trò của các cơ sở dữ liệu xuất bản quốc tế như WoS hoặc Scopus và một số cơ sở dữ liệu uy tín khác. Cùng với đó, hội nhập xuất bản quốc tế cũng đã xuất hiện ở một số trường đại học ở Việt Nam với nguyện vọng rõ rệt. Một số trường đại học đã thành công trong việc 
nâng cao vị trí của mình tại bảng xếp hạng đại học thế giới. Trường Đại học Tôn Đức Thắng là đại diện Việt Nam duy nhất lọt vào top 1000 trường đại học toàn cầu dựa trên ShanghaiRanking Consultancy (2019); Đại học Duy Tân được xếp hạng 451-500 trong Bảng xếp hạng các trường Đại học Châu Á của QS;...

Có thể thấy, 3 giai đoạn trên là bức tranh toàn cảnh về việc sử dụng xuất bản quốc tế ở Việt Nam kể từ Đổi mới 1986 đến nay, thể hiện 3 bước tiến đáng kể trong việc xuất bản quốc tế với những thành quả nhất định.

Để Việt Nam tiến lên trong tương lai, phải ưu tiên ba khía cạnh: (1) giáo dục; (2) nỗ lực của các nhà khoa học trong việc phục vụ công chúng; (3) khoa học truyền thông, vì vậy, cần xác định xuất bản quốc tế là một công cụ hiệu quả trong giao tiếp khoa học có thể cải thiện sự hiểu biết lẫn nhau trong khu vực học thuật và giữa khu vực học thuật với các bên liên quan khác, bao gồm chính phủ, ngành công nghiệp và công chúng. Trong đó, quá trình quốc tế hóa xuất bản học thuật ở Việt Nam cho đến nay vẫn phụ thuộc chủ yếu vào việc đếm số lượng các ấn phẩm được lập chỉ mục của WoS/Scopus. Trong tương lai gần, sự tham gia của các chỉ số xuất bản khoa học (ví dụ như chỉ số $\mathrm{H}, \mathrm{IF}$ ), các tạp chí truy cập mở để tăng tính hiệu quả về chi phí và tính khách quan trong việc đánh giá chất lượng của các ấn phẩm, các hồ sơ nghiên cứu, cũng như các nhóm nghiên cứu sẽ mở ra cơ hội mới cho sự phát triển của giới học thuật ở Việt Nam.

\section{Tài liệu tham khảo:}

Thi Thu Ha Nguyen, Hiep-Hung Pham, Quan-Hoang Vuong, Quoc-Thai Cao, Viet-Hung Dinh, Dinh Duc Nguyen (2020). The adoption of international publishing within Vietnamese academia from 1986 to 2020: A review. Learner Publishing, https://doi.org/10.1002/leap.1340 (https://doi.org/10.1002/leap.1340).

Hoặc đọc bản online: https://onlinelibrary.wiley.com/doi/10.1002/leap.1340 (https://onlinelibrary.wiley.com/doi/10.1002/leap.1340).

Ghi chú: *-bổ sung, bình luận

Tác giả bài viết: Hoàng Khánh Linh

URL của bản tin này: https://tapchigiaoduc.moet.gov.vn/vi/news/thong-tin-khoa-hoc/xuat-ban-quoc-te-ve-khoa-hoc-cua-viet-nam-chinh-sach-vaxu-the-606.html (https://tapchigiaoduc.moet.gov.vn/vi/news/thong-tin-khoa-hoc/xuat-ban-quoc-te-ve-khoa-hoc-cua-viet-nam-chinh-sach-va-xuthe-606.html)

๑ TẠP CHÍ GIÁO DỤC edu29.admin@gmail.com (mailto:edu29.admin@gmail.com) 


\section{Tài liệu tham khảo}

Thi Thu Ha Nguyen, Hiep-Hung Pham, Quan-Hoang Vuong, Quoc-Thai Cao, Viet-Hung Dinh, Dinh Duc Nguyen (2020). The adoption of international publishing within Vietnamese academia from 1986 to 2020: A review. Learner Publishing, https://doi.org/10.1002/leap.1340. 